EXTENDED REPORT

\title{
Infliximab in spondyloarthropathy associated with Crohn's disease: an open study on the efficacy of inducing and maintaining remission of musculoskeletal and gut manifestations
}

\author{
S Generini, R Giacomelli, R Fedi, A Fulminis, A Pignone, G Frieri, A Del Rosso, \\ A Viscido, B Galletti, M Fazzi, F Tonelli, M Matucci-Cerinic
}

Ann Rheum Dis 2004;63:1664-1669. doi: 10.1136/ard.2003.012450

See end of article for
authors' affiliations
$\ldots \ldots \ldots \ldots \ldots \ldots \ldots \ldots$
Correspondence to:
Dr S Generini, Department
of Internal Medicine,
Section of Rheumatology,
University of Florence, Italy
50139 ; generini@
hotmail.com
Accepted
19 February 2004
Published Online First
5 August 2004
........................

See end of article for authors' affiliations

Correspondence to:

Dr S Generini, Department ( Uection of Rheumatology, 50139; generini@

.......................

\begin{abstract}
Objective: To evaluate the efficacy and tolerability of anti-tumour necrosis factor $\alpha$ (TNF $\alpha$ ) monoclonal antibody (infliximab) in the treatment of spondyloarthropathy ( $\mathrm{SpA}$ ) associated with active and inactive Crohn's disease (CD).

Methods: Twenty four patients with SpA associated with active or inactive CD ( 16 active, 8 quiescent) were treated with anti-TNF $\alpha$ monoclonal antibody (infliximab) with repeated infusions for a period of 12-18 months. The treatment aimed at ameliorating the general musculoskeletal and spinal pain, controlling peripheral arthritis and enthesitis, decreasing the BASDAl score, modifying acute phase reactants, and reducing CD activity.

Results: Infliximab improved both gastrointestinal $(p<0.01)$ and overall articular symptoms (BASDAl, $p<0.01$; general musculoskeletal and spinal pain, $p<0.01$; peripheral arthritis, $p<0.01$ ) in patients with active $C D$. Additionally, infliximab effectively controlled not only axial involvement and peripheral arthritis but also enthesitis $(p<0.01)$ and prevented inflammatory bowel disease reactivation in patients with inactive $C D$ and low inflammatory markers. Amelioration of gut and musculoskeletal involvement persisted for up to 12 months.

Conclusion: Infliximab may act on the inflammation of entheses and of periarticular structures, which usually does not cause a change in the haematological markers that are the main indicators of pain and joint ankylosis in SpA. Infliximab induces and maintains remission of CD while at the same time treating active and severe SpA, suggesting that it should be the preferred drug for the treatment of active and severe $\mathrm{SpA}$ associated with active or quiescent $C D$.
\end{abstract}

M usculoskeletal manifestations are the most common extraintestinal complication of inflammatory bowel disease (IBD) - in particular, Crohn's disease (CD). These manifestations are usually included in the clinical spectrum of spondyloarthropathies (SpAs). The strong link between the bowel and the locomotor system in SpA is also supported by the evidence that inflammatory alterations of intestinal mucosa and its permeability (usually at the ileum) are present when symptoms are mild or subclinical in a high percentage of patients affected by any SpA without a manifest IBD. ${ }^{1}$ Different patterns of articular involvement have been recognised in IBD: type I, peripheral pauciarticular arthritis; type II, peripheral non-symmetric polyarthritis; and type III, an SpA resembling idiopathic ankylosing spondylitis, sometimes with peripheral joint involvement. ${ }^{2}$ In addition to axial and peripheral articular symptoms, enthesitis, tenosynovitis, and dactylitis commonly occur, sometimes representing the only manifestation ${ }^{3}$ and often causing severe and continuous discomfort, with a significant reduction of the quality of life of the patient. Type I arthritis may precede the diagnosis of IBD and, once established, often parallels the activity of the intestinal manifestation. Types II and III arthritis do not reflect the activity of the underlying IBD and rarely precede the diagnosis of IBD.

Efficacy and safety in the management of these conditions, especially when associated, is difficult to achieve. In fact, SpAs are often poorly responsive to disease modifying drugs, and the possibility of a drug triggered intestinal activation or relapse significantly limits the use of several drugs.
Tumour necrosis factor $\alpha(\mathrm{TNF} \alpha)$ is a so called "master cytokine" which has a key role in the regulation of innate immunity and in the local inflammatory response of several pathogenetically distinct diseases. ${ }^{4}$ In particular, TNF $\alpha$ is important in the genesis and maintenance of synovitis in rheumatic disorders and of mucosal inflammation in IBDs.

Infliximab is a chimeric anti-TNF $\alpha$ monoclonal IgGl antibody, neutralising soluble cytokines and blocking membrane bound cytokines. ${ }^{5}$ For this reason, infliximab has been initially successfully used in patients with rheumatoid arthritis (RA). ${ }^{67}$ Infliximab is remarkably effective in patients with RA presenting with persistent active disease despite adequate treatment with methotrexate. ${ }^{8}$ The clinical response after 1 year of treatment (American College of Rheumatology $20 \%$ ) has reached efficacy of $42-59 \%{ }^{9}$

Infliximab has been also used in CD. It induces remission of symptoms, closure of fistulae, healing of lesions, and improvement in the quality of life. A beneficial effect on extraintestinal complications, including articular complications, has been seen. ${ }^{10-14}$

\footnotetext{
Abbreviations: BASDAI, Bath Ankylosing Spondylitis Disease Activity Index; CD, Crohn's disease; CDAl, Crohn's Disease Activity Index; $C R P, C$ reactive protein; $E S R$, erythrocyte sedimentation rate; IBD, inflammatory bowel disease; NSAIDs, non-steroidal antiinflammatory drugs; RA, rheumatoid arthritis; SpA, spondyloarthropathy; TNF $\alpha$, tumour necrosis factor $\alpha$; US, ultrasonography; VAS, visual analogue scale
} 


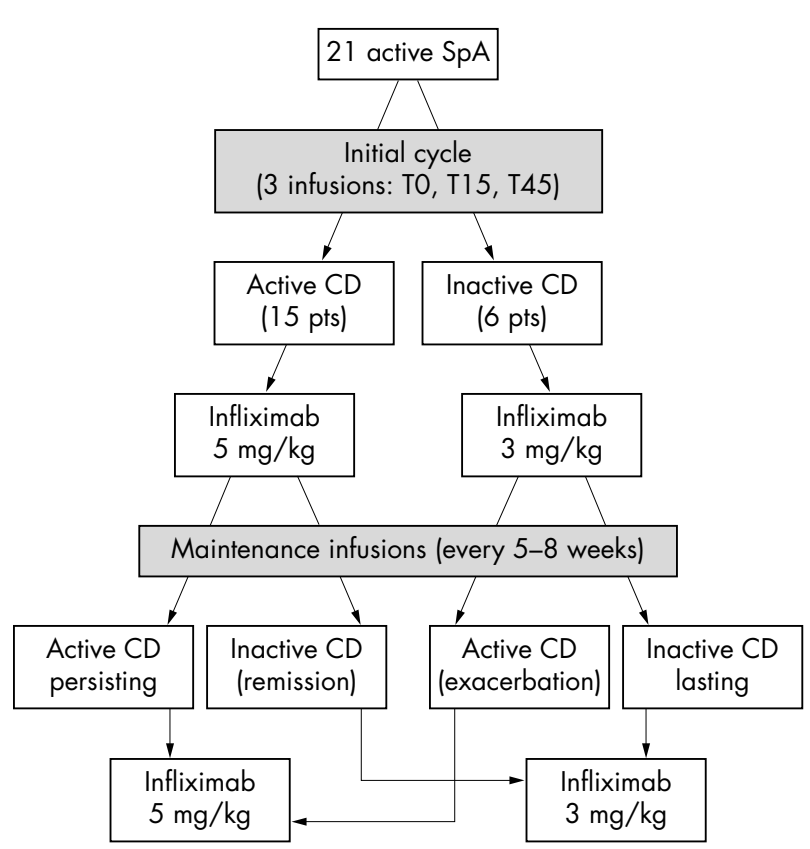

Figure 1 Therapeutic flow chart for the treatment of active SpA associated with active or inactive CD.

These observations and the close relation between gut inflammation and joint involvement in patients with SpA, have suggested the use of infliximab in ankylosing spondylitis. Although the bulk of experience in this disease is not comparable with that of RA and CD, substantial evidence now suggest that infliximab is highly effective and well tolerated for both axial and peripheral joint disease in patients with active ankylosing spondylitis. ${ }^{15-17}$ Some reports of the use of infliximab in other SpA have also been published. ${ }^{18-21}$ By contrast with ankylosing spondylitis, few studies have examined the specific treatment of SpA associated with CD. One open, short term study of four patients with SpA associated with active CD (three patients with peripheral arthritis, one with prominent axial involvement) showed that infliximab induces a fast improvement of articular manifestations and remission of active intestinal disease. $^{22}$ Another prospective, open label study from Herfarth et al evaluated the incidence of arthritis and arthralgia in a group with chronic active CD (153 patients) and the effect of infliximab on articular symptomatology after 12 weeks of treatment. ${ }^{23}$ All the patients presenting any musculoskeletal symptom, and not only those with a clear SpA, were included in the study. Musculoskeletal symptoms were evaluated by clinical examination and graded on a four point scale (severe, moderate, mild, and none) with no distinction between the different patterns of articular involvement (peripheral arthritis, axial involvement, enthesitis). Infliximab significantly reduced the arthritis/arthralgia score in this cohort of patients.

TNF $\alpha$ blockade with the other biological agent, etanercept, is effective in the treatment of SpA but not in the treatment of colitis. The persistence or flaring of $C D$ despite the complete resolution of spinal pathology in two patients treated with etanercept has been reported. ${ }^{24}$

Our work aimed at investigating the efficacy and safety of a short and long term regimen of infliximab in the treatment of patients with SpA who also presented with, or had experienced in the past, intestinal inflammation due to CD.

\section{PATIENTS AND METHODS}

Twenty four patients with active SpA associated with CD (14 male, 10 female; mean (SD) age 44 (10) years) referred to the departments of medicine of the University of Florence and L'Aquila (Italy) were selected for the study. At baseline, 16 patients presented active CD (mean (SD) disease duration 9.9 (5.3) years), while 8 patients had quiescent CD (mean disease duration 10.3 (4.6) years). A further 12 additional patients presenting active CD (mean disease duration 9.16 (3.3) years) and similar articular disease served as controls and were treated conventionally (see below).

All patients had active and severe SpA (mean disease duration 9.9 (6.3) years) fulfilling European Spondylarthropathy Study Group (ESSG) criteria ${ }^{25}$ and characterised by axial involvement (25/36 subjects) and/or peripheral arthritis (23/36), and/or enthesopathy (25/36), poorly or not responsive to conventional treatments (non-steroidal anti-inflammatory drugs (NSAIDs), sulfasalazine, systemic and local steroids, physiotherapy) or for whom previous treatments had induced a worsening or a relapse of the gastrointestinal symptoms.

Disease activity was assessed by the Bath Ankylosing Spondylitis Disease Activity Index (BASDAI); visual analogue scale (VAS) for general musculoskeletal pain; separate VAS for spinal pain; presence of peripheral arthritis/synovitis; presence of active enthesitis or periarticular inflammation. The diagnosis of peripheral arthritis and active enthesitis was confirmed by ultrasonography (US). Peripheral arthritis was considered present when at least one peripheral joint showed swelling and tenderness, with documented joint effusion. The number of affected joints was not taken into account because most of the patients with peripheral arthritis had mono- or pauciarticular disease. Enthesitis and periarticular inflammation were defined both clinically (pain at pressure or mobilisation) and by US in the most commonly affected sites of insertion (greater trochanter, ischial tuberosity, pubis, patellar poles and tibial tuberosity, posterior and inferior calcaneus, medial and lateral epicondyles, chondrosternal and manubriosternalis junctions). US (ESAOTE AU5 epi, linear probe $7.5-12 \mathrm{MHz}$, pwD dynamic range $50 \mathrm{sB}$, PRF $750 \mathrm{~Hz}$ ) was performed by an experienced echographer who was unaware of the clinical and biological findings. Oedema, thickening, erosions at the enthesis junction and increased flow by pwD were considered pathological. Enthesitis was considered active in the presence of both pain and US abnormalities due to current inflammation (oedema, thickening, and increased flow). Enthesitis was considered present when at least one site showed signs of active inflammation.

SpA was considered active in patients presenting a BASDAI $>40$ and VAS for general musculoskeletal pain $>40$, persisting for at least 4 months.

All the variables were assessed at baseline and then at each infliximab infusion.

The activity of $\mathrm{CD}$ was evaluated by "Crohn's Disease Activity Index" (CDAI) ${ }^{26}$ recorded by the patients during the 7 days before each infusion and during the 4th week after the last infusion. The disease was considered active when the score was higher than 150 .

Laboratory evaluation, including erythrocyte sedimentation rate (ESR), C reactive protein (CRP), routine hepatic and renal measures, and complete blood count, was also carried out at baseline and before each infusion of infliximab or at the corresponding time for the control group.

\section{Treatment}

The patients with active CD received three infusions of $5 \mathrm{mg} /$ $\mathrm{kg}$ infliximab (at weeks 0, 2, and 6) and later on infusions of $3 \mathrm{mg} / \mathrm{kg}$ infliximab, if the bowel disease had remitted, or $5 \mathrm{mg} / \mathrm{kg}$ when it persisted, every 5-8 weeks according to the 

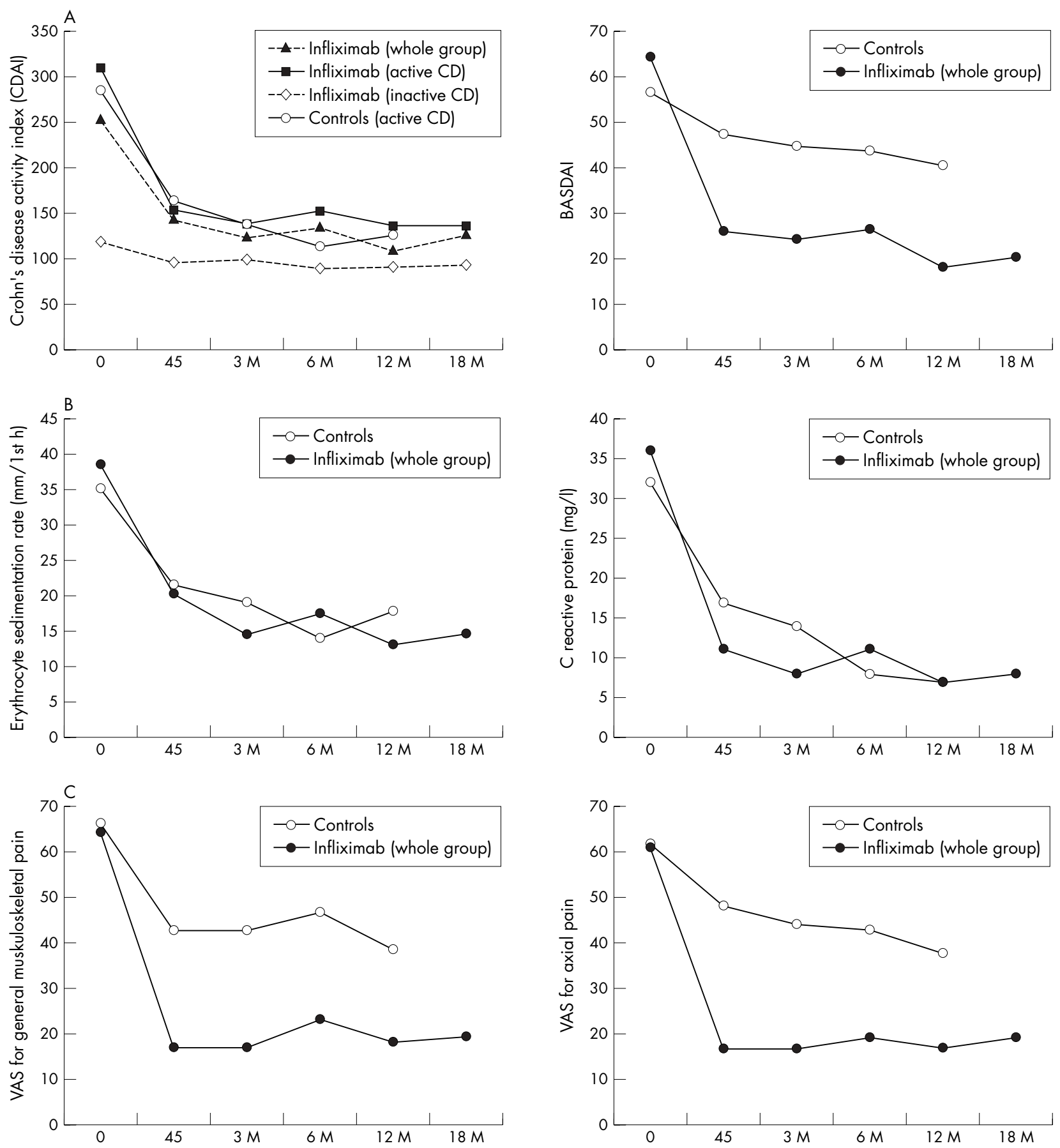

Figure $2(A, B, C)$ Clinical and laboratory data (mean) of the patients with SpA and CD at baseline and during treatment with infliximab or various other conventional treatments (baseline, 45 days, 3, 6, 12, 18 months ). The values of CDAl are split into two additional groups: patients with active or inactive $C D$ at baseline.

duration of therapeutic effect (medium (SD) interval between the infusions 44.2 (9.3) days). The patients who presented inactive $\mathrm{CD}$ at baseline were treated with $3 \mathrm{mg} / \mathrm{kg}$ infliximab from the first dose with the same schedule (fig 1). All the patients were treated with infliximab for at least 12 months. After 12 months, the patients continued the treatment (apart from those who stopped owing to side effects or inefficacy); however, data at 18 months are available only for 12 patients.

All the patients were allowed to continue the pharmacological treatment and physiotherapy they were undergoing before the study if no modifications had occurred during the previous months (3 months for 5 -aminosalicylic acid compounds, 1 month for NSAIDs and steroids).

The control patients, all with active $\mathrm{CD}$ at baseline, received a variety of other drugs commonly employed in $\mathrm{CD}$ (oral azathioprine $2.5 \mathrm{mg} / \mathrm{kg} / \mathrm{day}$, topical and systemic salicylates, topical and systemic steroids, antibiotics, metronidazole).

The continued use of oral 5-aminosalicylic acid compounds and steroid or 5-aminosalicylic enemas was allowed within the definition of remission. 

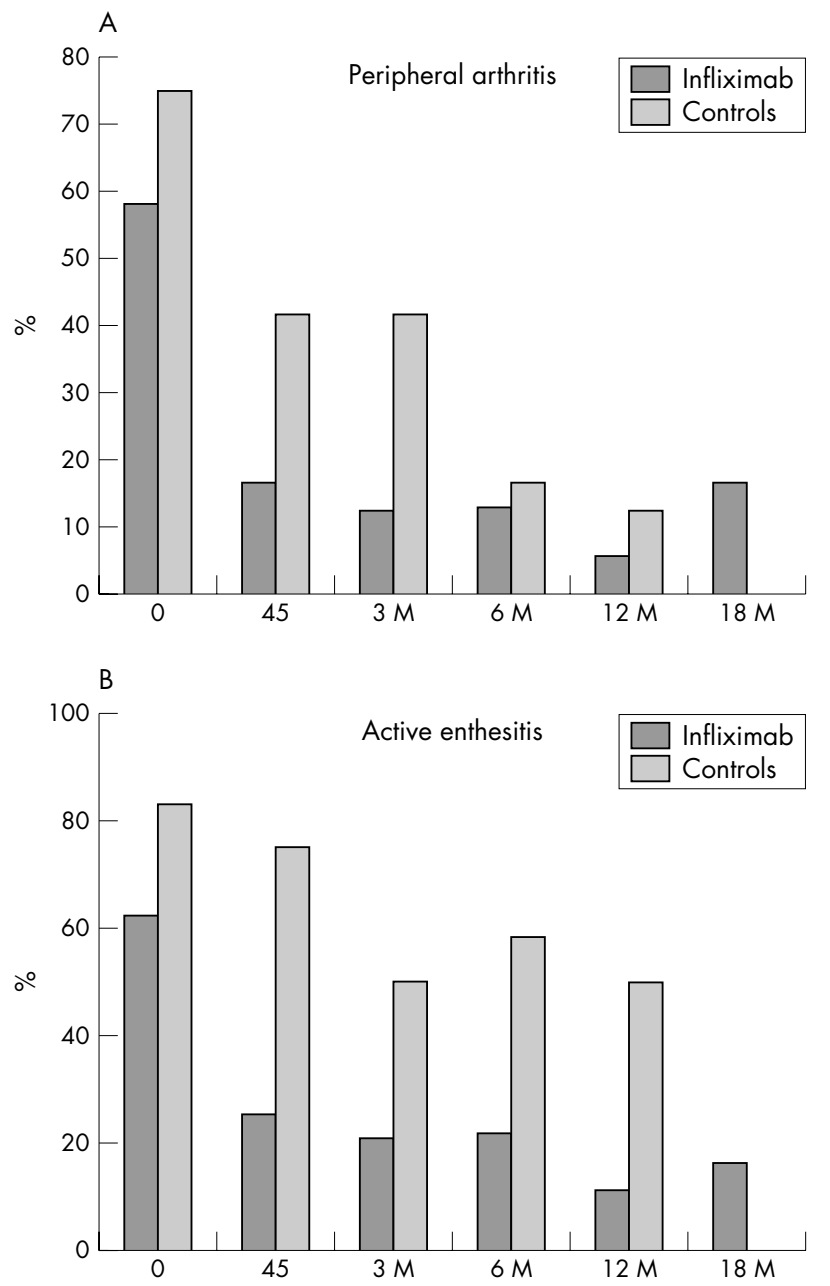

Figure 3 Percentage of patients presenting peripheral arthritis $(A)$ or active enthesitis (B) at baseline and during the treatment ( 45 days, 3, 6 , 12,18 months) with infliximab or various other drugs (azathioprine, mesalazine, steroids, metronidazole, antibiotics). "The data reported at 12 months are relative to patients $(10 / 21)$ who prolonged the treatment with infliximab for up to 12 months; no controls are available for this group.

\section{Statistical analysis}

Primary end points analysed were the BASDAI score, the VAS for musculoskeletal pain, ESR, CRP, and CDAI at 45 days, 6 months, and 12 months after the start of treatment. Variables are presented as the mean (SD), unless stated otherwise. SPSS-PC was used for data analysis. Comparison between baseline and subsequent assessments was performed with the Wilcoxon matched pairs signed rank test. The efficacy of the treatment in comparison with the control treatment was assessed by analysis of variance. The results were considered significant at $\mathrm{p}<0.05$. Correlations between variables were assessed using the Pearson rank correlation coefficient. A partial correlation test was used to study the relation between the same variables after treatment had started.

\section{RESULTS}

\section{Musculoskeletal involvement}

All patients treated with infliximab had significantly improved articular and periarticular manifestations of SpA, both axial and peripheral (table 1, figs $2 \mathrm{C}$ and 3). In these patients, the BASDAI score showed a dramatic and prompt
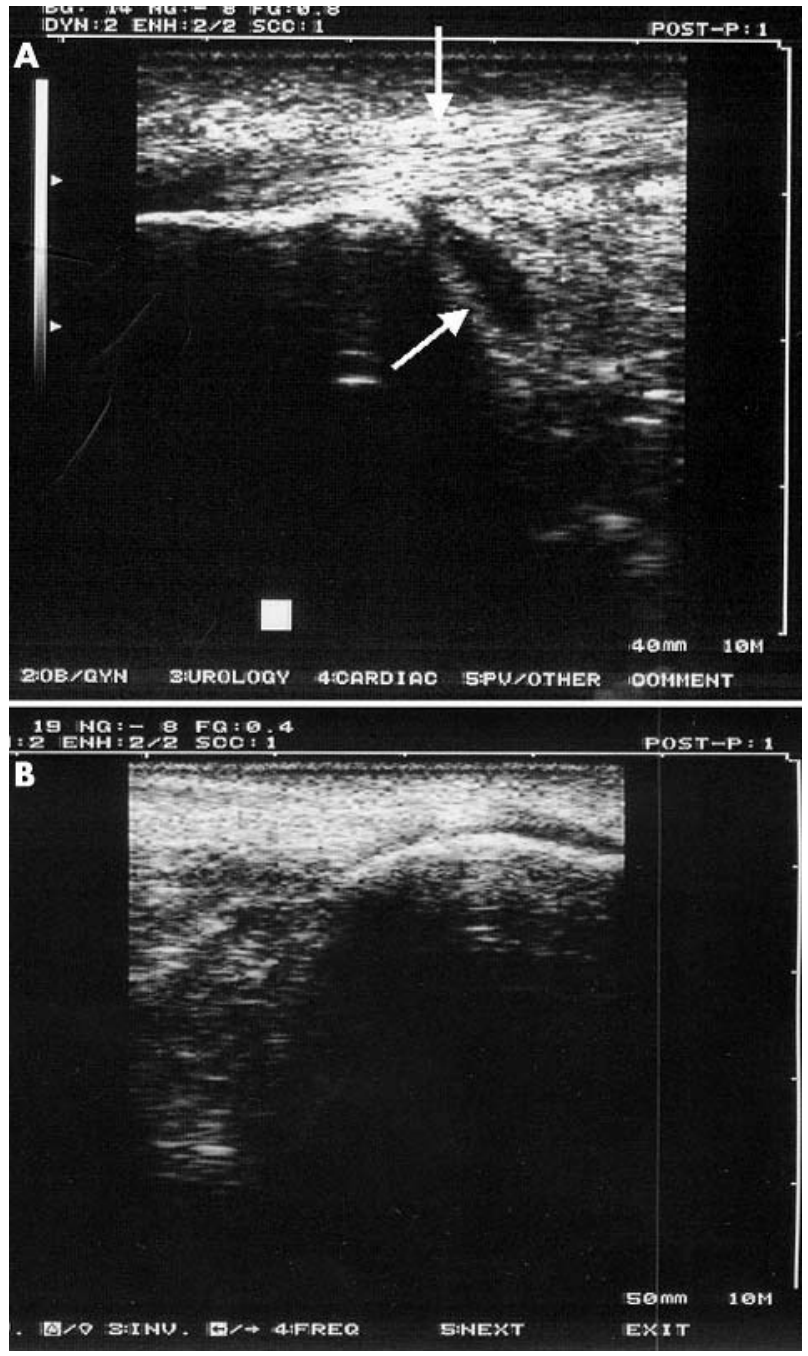

Figure 4 (A) Thickening and homogeneous hypoechogenicity of the Achilles tendon enthesis with distension of the retrocalcaneal bursa (arrows) which disappeared after 45 days of treatment with infliximab (B).

decrease $(\mathrm{p}<0.01)$, which persisted throughout the treatment (fig 2A). The BASDAI score was also significantly reduced in the control group $(p<0.05)$ but almost never below 40 (the appointed limit for active disease). The reduction of BASDAI due to infliximab was more significant than that due to other treatments $(p<0.05)$. Infliximab significantly and rapidly reduced peripheral arthritis (from 58\% to $12.5 \%$ after 6 months, from $55.5 \%$ to $11.1 \%$ after 1 year and from $50 \%$ to $16.6 \%$ in the patients who prolonged their treatment for up to 18 months) (fig $3 \mathrm{~A}$ ). Patients of the control group had a slower but progressive amelioration of peripheral arthritis, which was comparable to that of the infliximab group after 6 and 12 months (from $75 \%$ to $17 \%$ and $12.5 \%$, respectively) (fig 3A). From the first infusions, infliximab produced a clear decrease of active enthesitis (fig 4), which persisted at 6 months (from $67 \%$ to $24 \%$ ), at 12 months (from $60 \%$ to $10 \%$ ), and at 18 months (from $58.3 \%$ to $16.6 \%$ ) (fig 3B). In many of the patients who did not achieve a complete remission of enthesitis the number of sites of inflammation was reduced or the clinical manifestations of enthesitis improved (data not shown). The control treatments had little effect on enthesitis (fig 3B). Finally, infliximab decreased both the general musculoskeletal and the spinal pain to a 
Table 1 Clinical and laboratory data of the patients with SpA and CD at baseline and during treatment with infliximab or various other conventional treatments (oral azathioprine $100 \mathrm{mg}$ daily, topical and systemic salicylates, topical and systemic steroids, antibiotics, metronidazole)

\begin{tabular}{|c|c|c|c|c|c|c|c|c|c|c|c|}
\hline & \multicolumn{6}{|l|}{ Infliximab } & \multicolumn{5}{|l|}{ Controlst } \\
\hline & TO & T45 & T3M & T6M & $\mathrm{T12M}$ & T18M & TO & T45 & T3M & T6M & $\mathrm{T} 12$ \\
\hline Number of patients & 24 & 24 & 24 & 23 & 22 & 12 & 12 & 12 & 12 & 12 & 8 \\
\hline Withdrawalsł & - & 0 & 0 & 1 & 2 & 0 & - & 0 & 0 & 0 & 4 \\
\hline CDAl (total group) & $252(119.5)$ & $144(47.0)^{*}$ & $125(30.1)^{\star *}$ & $135(78.2)^{\star *}$ & $110(27.3)^{* *}$ & $128(19.7)^{* *}$ & - & - & - & - & - \\
\hline $\begin{array}{l}\text { CDAl (active CD at } \\
\text { baseline) }\end{array}$ & $308(90.3)$ & $154(42.5)^{*}$ & $137(29.5)$ & $151(79.1)^{* *}$ & $137(31.3)^{* *}$ & $136(18.7)^{* *}$ & $285(70.6)$ & $163(29.2)^{* *}$ & $139(27.1)^{* *}$ & ${ }^{* *} 113(29.2)^{* *}$ & $125(26.5)^{* *}$ \\
\hline $\begin{array}{l}\mathrm{CDAl} \text { (inactive } \mathrm{CD} \text { at } \\
\text { baseline) }\end{array}$ & 118 (23.2) & $96(17.5)$ & $99(13.1)$ & $89(8.7)$ & $90(17.2)^{*}$ & $92(19.4)$ & - & - & - & - & - \\
\hline ESR $(\mathrm{mm} / 1 \mathrm{st} h)$ & $38.5(23.7)$ & $20.0(13.2)^{*}$ & $14.4(7.6)^{* *}$ & $17.2(13.7)^{* *}$ & $12.8(9.3)^{* *}$ & $14.3(8.5)^{* \star}$ & $35.1(17.1)$ & $21.42(10.7)^{*}$ & $19.1(8.3)^{* *}$ & * $13.9(6.6)^{* *}$ & $17.6(7.9)^{* *}$ \\
\hline $\mathrm{CRP}(\mathrm{mg} / \mathrm{l})$ & $36(25)$ & $11(8)^{* *}$ & $8(5.4)^{* \star}$ & $11(7)^{* *}$ & $7(3)^{\star *}$ & $8(3)^{\star \star}$ & $32(24)$ & $17(9)^{*}$ & $14(10)^{*}$ & $8(4)^{* *}$ & $7(5)^{\star *}$ \\
\hline $\begin{array}{l}\text { Musculoskeletal pain } \\
\text { (VAS) }\end{array}$ & $63.8(15.6)$ & $16.8(9.6)^{\star *}$ & $17.2(10.2)^{\star *}$ & $23(17.6)^{* *}$ & $18.2(7)^{\star *}$ & $18.9(9.1)^{\star *}$ & $65.6(10.7)$ & $42.6(16.7)^{*}$ & $42.8(14.6)^{*}$ & ${ }^{*} 46.5(22.4)^{*}$ & $38.6(22.7)^{*}$ \\
\hline BASDAI & $64.2(12.2)$ & $25.7(12.2)^{\star *}$ & $24.0(10.1)^{* *}$ & $26.5(15.3)^{* *}$ & $18.1(8.3)^{\star *}$ & $20.0(9.9)^{\star \star}$ & $56.7(13.8)$ & $47.3(11.8)$ & $44.7111 .6^{*}$ & $43.65(16.1)^{*}$ & $40.05(18.2)^{*}$ \\
\hline Axial pain (VAS) & $60.8(24.6)$ & $17.3(11.9)^{* *}$ & $17.0(8.8)^{\star \star}$ & $19.8(17.3)^{* *}$ & $17.4(8.1)^{* *}$ & $19.6(16.3)^{* *}$ & $61.8(21.4)$ & 48.18 (19.9) & $44.3(18.7)^{*}$ & * $43.0(22.9)^{*}$ & $37.8(23.3)^{*}$ \\
\hline $\begin{array}{l}\text { Peripheral arthritis } \\
\text { (yes/no) }\end{array}$ & $14 / 10$ & $4 / 20$ & $3 / 21$ & $3 / 20$ & $1 / 17$ & $2 / 10$ & $9 / 3$ & $5 / 7$ & $5 / 7$ & $2 / 10$ & $1 / 7$ \\
\hline $\begin{array}{l}\text { Active enthesitis } \\
\text { (yes/no) }\end{array}$ & $15 / 9$ & $6 / 18$ & $5 / 19$ & $5 / 18$ & $2 / 16$ & $2 / 10$ & $10 / 2$ & $9 / 3$ & $6 / 6$ & $7 / 5$ & $4 / 4$ \\
\hline
\end{tabular}

significant extent $(\mathrm{p}<0.01) \quad($ fig $2 \mathrm{C})$. This effect was significantly higher than in control group $(\mathrm{p}<0.05)$ (fig $2 \mathrm{C})$.

No patients used analgesic or anti-inflammatory drugs during the treatment with infliximab. At 12 months, three patients of the control group started infliximab treatment because of the persistence of severe spondyloarthritic symptoms (table 1).

\section{Gastrointestinal involvement}

In patients with active $C D$, infliximab induced a remarkable improvement of gastrointestinal signs and symptoms, with significant reduction of CDAI after the first two infusions $(p<0.01)$, which was maintained over 45 days $(p<0.01), 3,6$, and 12 months $(p<0.01)$ (table 1$)$. After 6 months, four patients still presented active CD and for this reason three of them had to take oral steroids. After 12 months, two patients stopped the treatment with infliximab because of CD relapse and took other immunosuppressant drugs (table 1). None of the eight patients with inactive $\mathrm{CD}$ at baseline had exacerbation of their disease during the study.

The patients of the control group also showed a reduction of the CDAI, which persisted over the 12 months of study $(p<0.01)$. At 12 months, one patient interrupted treatment with conventional drugs and started infliximab because bowel inflammation was reactivated. Notably, no significant difference in the ability to induce and maintain remission of $\mathrm{CD}$ was seen between infliximab and the control treatments. In most patients, the treatments significantly and rapidly reduced laboratory inflammatory measures (ESR and CRP) (table 1). Indeed, a significant reduction of these measures was also seen in patients with inactive CD $(p<0.05)$ (data not shown).

\section{Correlations between variables}

At baseline, the following correlations were found: ESR correlated with CRP $(r=0.79 ; \mathrm{p}=0.002)$ and, slightly, with CDAI $(r=0.67 ; \mathrm{p}=0.06)$ and peripheral arthritis $(r=0.69$; $\mathrm{p}=0.054)$; CRP also showed a very mild correlation with peripheral arthritis $(r=0.66 ; \mathrm{p}=0.83)$; BASDAI correlated only with general musculoskeletal pain $(r=0.69$; $\mathrm{p}=0.054)$. Notably, BASDAI, as well as axial pain and enthesitic involvement, did not correlate with theacute phase reactants. None of the pharmacological treatments significantly modified these correlations.

\section{Tolerability}

Infliximab was well tolerated throughout the study. One patient stopped the treatment after 6 months owing to an allergic reaction after the infusion (cough, dyspnoea, flush) (table 1). Other minor side effects were headache, dizziness, and transient leucopenia that regressed spontaneously and required treatment to be interrupted. No infections occurred.

In the control group, two patients treated with azathioprine had nausea and vomiting, one patient treated with mesalazine and metronidazole had a transient rise in $\gamma$ glutamyltransferase that required reduction of the drugs.

\section{DISCUSSION}

In enteropathic arthopathies, management of bowel inflammation is the main task because this may indirectly induce remission of musculoskeletal manifestations. However, in a large number of patients, despite the amelioration or disappearance of gut inflammation, joint disease persists. ${ }^{2}$ In these cases, NSAIDs must be carefully used because of the possibility of gastrointestinal side effects and of IBD activation. Indeed, steroids and disease modifying antirheumatic drugs are often ineffective in controlling axial pain and enthesitis $^{27}$ and, with the exception of sulfasalazine, they cannot completely prevent relapse of bowel inflammation.

When both intestinal disease and arthropathy are in an active phase, the preferred drugs are those potentially effective on the inflammation in both areas. Sometimes, even though $\mathrm{CD}$ is in remission and laboratory inflammatory markers are normal or scarcely altered, the musculoskeletal symptoms associated with SpA may persist. In these cases, control of the musculoskeletal symptoms, especially enthesitis and spinal pain that potentially mirror progression of the disease towards ankylosis, ${ }^{28}$ becomes the primary task together with the restoration of the quality of life.

Our preliminary data are generated in an open study but confirm that infliximab controls the inflammation and the symptoms of SpA associated with active CD. Moreover, infliximab significantly controls musculoskeletal pain derived not only from axial and peripheral articular involvement but also enthesitis, even in patients with quiescent CD and with no or moderate increase of acute phase reactants.

Almost all of our patients reported the disappearance of enthesitis, strongly suggesting that infliximab specifically acts on inflammation of periarticular structures. It is 
well known that entheseal involvement does not alter haematological measures but is evidence of the persistence of disease activity and may contribute to joint ankylosis. ${ }^{28}$

The positive results, promptly achieved after the first infusions, persisted over the whole treatment and the infusions were reasonably well tolerated. In the control group (especially in patients treated with azathioprine, data not shown) the treatment effectively controlled gut inflammation, peripheral arthritis, and acute phase reactants but it had a poor effect on axial and enthesitic pain. The results of treatment were better in patients with pauciarticular peripheral disease, which often parallels the activity of the intestinal manifestation, the so called "type I". ${ }^{2}$

In conclusion, infliximab, because of its remarkable antiinflammatory effect on both the articular and intestinal systems, may be a pivotal treatment in severe SpA associated with active $C D$, often presenting with peripheral arthritis and increased acute phase reactants. Moreover, because infliximab acts on all musculoskeletal inflammatory components of SpA and, at the same time, maintains the remission of gut inflammation, it may be a useful therapeutic tool also for patients with inactive $\mathrm{CD}$ and modest laboratory signs of inflammation but who have persistent and severe axial and enthesitic pain. Extension of the treatment beyond the standard three infusions, usually reserved for active $C D$, may be advisable in both types of patient if inflammation persists. In IBDs and SpA, double blind studies with infliximab are warranted to verify these data and evaluate the efficacy and tolerability of the drug in long term use.

\section{Authors' affiliations}

S Generini, R Fedi, A Pignone, A Del Rosso, M Matucci-Cerinic, Department of Internal Medicine, Section of Rheumatology, University of Florence, Italy

R Giacomelli, A Fulminis, Immunorheumatology Unit, Department of Internal Medicine and Public Health, University of l'Aquila - School of Medicine, L'Aquila, Italy

G Frieri, A Viscido, B Galletti, Gastroenterology Unit, Department of Internal Medicine and Public Health, University of l'Aquila - School of Medicine, L'Aquila, Italy

M Fazzi, F Tonelli, Department of Clinical Physiopathology, Surgical Unit, University of Florence, Florence, Italy

\section{REFERENCES}

1 Martinez-Gonzalez O, Cantero-Hinojosa J, Paule-Sastre P, GomezMagan JC, Salvatierra-Rios D. Intestinal permeability in patients with ankylosing spondylitis and their healthy relatives. $\mathrm{Br} J$ Rheumatol 1994;33:644-7.

2 Orchard TR, Wordworth BP, Jewell DP. Peripheral arthropathies in inflammatory bowel disease: Their articular distribution and natural history. Gut 1998:42:387-91.

3 Salvarani C, Fornaciari G, Beltrami M, Macchioni PL. Musculoskeletal manifestations in inflammatory bowel disease. Eur J Int Med 2000;11:210-14

4 Dinarello CA, Moldawer LL. The tumor necrosis factor (TNF) superfamily and its receptors. In:Proinflammatory and anti-inflammatory cytokines in rheumatoid arthritis.3rd ed. Thoussand Oaks, CA, USA: Amgen Inc, 2002:95-118.

5 Knight DM, Trinh H, Le J, Siegel S, Shealy D, McDonough M, et al. Construction and initial characterization of a mouse-human chimeric anti-TNF antibody. Mol Immunol 1993;30:1443-53.

6 Cope AP, Londei M, Chu NR, Cohen SB, Elliott MJ, Brennan FM, et al. Chronic exposure to TNF in vitro impairs the activation of $\mathrm{T}$ cells through the T cell
receptor/CD3 complex; reversal in vivo by anti-TNF antibodies in patients with rheumatoid arthritis. J Clin Invest 1994;94:749-60.

7 Elliott MJ, Maini RN, Feldmann M, Kalden JR, Antoni C, Smolen JS, et al. Randomised double-blind comparison of chimeric monoclonal antibody to TNF versus placebo in rheumatoid arthritis. Lancet 1994;344:1105-10.

8 Maini R, St Clair EW, Breedveld F, Furst D, Kalden J, Weisman M, et al. Infliximab (chimeric anti-TNF monoclonal antibody) versus placebo in RA patients receiving concomitant methotrexate: a randomised phase III trial. Lancet 1999;354:1932-9.

9 Lipsky PE, van der Heijde DM, St Clair EW, Furst DE, Breedveld FC, Kalden JR, et al. Infliximab and methotrexate in the treatment of rheumatoid arthritis. Anti-Tumor Necrosis Factor Trial in Rheumatoid Arthritis with Concomitant Therapy Study Group. N Engl J Med 2000;343:1594-602.

10 Targan SR, Hanauer SB, van Deventer SJH, Mayer L, Present DH, Braakman T, et al. A short-term study of chimeric monoclonal antibody CA2 to tumor necrosis factor alpha for Crohn's disease. Crohn's Disease cA2 Study Group. N Engl J Med 1997;337:1029-35.

11 Present DH, Rutgeerts P, Targan S, Hanauer SB, Mayer L, van Hogezand RA, et al. Infliximab for the treatment of fistulas in patients with Crohn's disease. N Engl J Med 1999;340:1398-405.

12 D'Haens G, van Deventer S, van Hogezand R, Chalmers D, Kothe C, Baert F, et al. Endoscopic and histological healing with infliximab anti-TNF antibodies in Crohn's disease: a European multicenter trial. Gastroenterology 1999; 116:1029-34.

13 Hanauer SB, Feagan BG, Lichtenstein GR, Mayer LF, Schreiber S, Colombel JF, et al. Maintenance infliximab for Crohn's disease: the ACCENT I randomised trial. Lancet 2002;359:1541-9.

14 Arnott IDR, McDonald D, Williams A, Gosh S. Clinical use of infliximab in Crohn's disease: the Edinburgh experience. Aliment Pharmacol Ther 2001;15:1639-46.

15 Braun J, Brandt J, Listing J, Zink A, Alten R, Golder W, et al. Treatment of active ankylosing spondylitis with infliximab: a randomised controlled multicentre trial. Lancet 2002;359:1187-93.

16 Brandt J, Haibel H, Reddig J, Sieper J, Braun J. Treatment of patients with severe ankylosing spondylitis with infliximab-a one year follow up. Arthritis Rheum 2002;44:2936-7.

17 Maksymowych WP, Jhangri GS, Lambert RG, Mallon C, Buenviaje H, Pedrycz E, et al. Infliximab in ankylosing spondylitis: a prospective observational inception cohort analysis of efficacy and safery. J Rheumatol 2002;29:959-65

18 van den Bosch F, Kruithof E, Baeten D, De Keyser F, Mielants H, Veys EM. Effects of a loading dose regimen of three infusions of chimeric monoclonal antibody to tumour necrosis factor $\alpha$ (infliximab) in spondyloarthropathy: an open pilot study. Ann Rheum Dis 2000;59:428-33.

19 van den Bosch F, Kruithof E, Baeten D, Herssens A, de Keyser F, Mielants H, et al. Randomized double-blind comparison of chimeric monoclonal antibody to tumor necrosis factor alpha (infliximab) versus placebo in active spondylarthropathy. Arthritis Rheum 2002;46:755-65.

20 Brandt J, Haibel H, Reddig J, Sieper J, Braun J. Successful treatment of severe undifferentiated spondyloarthropathy with the anti-tumor necrosis factor $\alpha$ monoclonal antibody infliximab. J Rheumatol 2002;44:2936-7.

21 Kruithof E, van den Bosch F, Baeten D, Herssens A, De Keyser F, Mielants H, Veys EM. Repeated infusions of infliximab, a chimeric anti-TNF $\alpha$ monoclonal antibody, in patients with active spondyloarthropathy: one year follow up. Ann Rheum Dis 2002;61:207-12.

22 van den Bosch F, Kruithof E, de Vos M, de Keyser F, Mielants H. Crohn's disease associated with spondyloarthropathy: effect of TNF-alpha blockade with infliximab on articular symptoms. Lancet 2000;356:1821-2.

23 Herfarth H, Obermeier F, Andus T, Rogler G, Nikolaus S, Kuehbacher T, et al. Improvement of arthritis and arthralgia after treatment with infliximab (Remicade) in a German prospective, open-label, multicenter trial in refractory Crohn's disease. Am J Gastroenterol 2002;97:2688-90.

24 Marzo-Ortega H, McGonagle D, O'Connor P, Emery P. Efficacy of etanercept for treatment of Crohn's related spondyloarthritis but not colitis. Ann Rheum Dis 2003;62:74-6.

25 Dougados M, van der Linden S, Juhlin R, Huiffeldt B, Amor B, Calin A, et al. The European Spondylarthropathy Study Group Preliminary Criteria For The Classification Of Spondylarthropathy. Arthritis Rheum 1991;34:1218-27.

26 Best WR, Becktel JM, Singleton JW, Kern F. Development of a Crohn's Disease Activity Index. National Cooperative Crohn's Disease Study. Gastroenterology 1976;70:439-44.

27 Braun J, Sieper J. Therapy of ankylosing spondylitis and other spondyloarthritides: established medical treatment, anti-TNF- $\alpha$ therapy and other novel approaches. Arthritis Res 2002;4:307-21.

28 Braun J, Khan MA, Sieper J. Enthesitis and ankylosis in spondyloarthropathy: what is the target of the immune response? Ann Rheum Dis 2000;59:985-94. 